\title{
Characterization of Three Thermophilic Strains of Methanothrix ("Methanosaeta") thermophila sp. nov. and Rejection of Methanothrix ("Methanosaeta") thermoacetophila
}

\author{
YOICHI KAMAGATA,${ }^{1 *}$ HIROKO KAWASAKI,${ }^{2}$ HIROSHI OYAIZU,${ }^{3}$ KAZUNORI NAKAMURA, \\ EIICHI MIKAMI, ${ }^{1}$ GINRO ENDO, ${ }^{4}$ YOSUKE KOGA,${ }^{5}$ AND KAZUHIDE YAMASATO ${ }^{2}$ \\ Fermentation Research Institute, Agency of Industrial Science and Technology, Tsukuba, Ibaraki 305'; \\ Institute of Applied Microbiology ${ }^{2}$ and Department of Agricultural Chemistry, ${ }^{3}$ The University of \\ Tokyo, Tokyo 113; Department of Civil Engineering, Tohoku Gakuin University, Tagajo-shi, \\ Miyagi 985 ; and Department of Chemistry, University of Occupational and \\ Environmental Health, Japan, Yahatanishi-ku, Kitakyushu 807,5 Japan
}

\begin{abstract}
Three thermophilic Methanothrix (“Methanosaeta") strains, strains $P_{\mathbf{T}}{ }^{\mathrm{T}}$ (= DSM $\left.61944^{\mathrm{T}}\right)(\mathrm{T}=$ type strain), CALS-1 (= DSM 3870), and Z-517 (= DSM 4774), were characterized chemotaxonomically and compared with five mesophilic strains, Methanothrix soehngenii ("Methanosaeta concilii") GP6 (= DSM 3671), Opfikon (= DSM 2139), FE (= DSM 3013), $U_{A}$, and $P_{M}$. These methanogens were exclusively acetotrophic and had a characteristic sheathed structure. The DNA base compositions of the strains which we studied ranged from 50.3 to $54.3 \mathrm{~mol} \%$ guanine plus cytosine. The thermophilic strains often had phase-refractive gas vesicles inside their cells. Denaturing electrophoresis of proteins showed that the mesophilic and thermophilic Methanothrix strains formed two distinct groups and that there were differences in protein patterns between the groups. The difference between the thermophiles and mesophiles was also verified by comparing partial 16S rRNA sequences (ca. 30 base differences in ca. 540 bases). On the basis of our results, we propose the name Methanothrix thermophila for the three thermophilic strains. The type strain of $M$. thermophila is strain $P_{T}(=$ DSM 6194). We also propose that the name Methanothrix thermoacetophila ("Methanosaeta thermoacetophila"'), which was given to strain Z-517 (type strain), should be rejected because of its description, which was based on an enrichment culture, was inadequate.
\end{abstract}

Of the methanogenic microorganisms, members of the genus Methanothrix play a very important role as acetate consumers in anaerobic digestion of organic compounds (6). Methanothrix spp. are sheathed, rod-shaped, aceticlastic methanogens, and the first Methanothrix strain was described by Söhngen (24). Later, Barker described this organism as Methanobacterium soehngenii (1). However, no axenic Methanothrix cultures were obtained for many years because of difficulties in cultivation.

A Methanothrix strain was first isolated as an "acetate organism" (strain Opfikon) by Zehnder et al., and later these authors described this strain as Methanothrix soehngenii (9, 27). After this description, several mesophilic Methanothrix strains were isolated or "highly purified" $(8,10,18,20,26)$. A thermophilic Methanothrix strain was first enriched from thermal lake mud by Nozhevnikova and Chudina (17), and these authors named their enriched organism (strain Z-517) Methanothrix thermoacetophila. Zinder et al. first obtained a pure culture of thermophilic Methanothrix sp. strain CALS-1 from a thermophilic anaerobic digestor (28).

Recently, Patel and Sprott proposed the genus Methanosaeta (21). According to the proposal of these authors, Methanosaeta concilii is the only valid species which contains mesophiles, and the type strain is strain GP6, which was described as Methanothrix concilii by Patel (20). However, there is controversy concerning the correct designation because Methanosaeta concilii, Methanothrix concilii, and Methanothrix soehngenii are considered synonyms (3).

\footnotetext{
* Corresponding author.
}

Patel and Sprott also proposed that Methanothrix thermoacetophila, which was originally described by Nozhevnikova and Chudina (17), should be reclassified as Methanosaeta thermoacetophila (21). However, the description of the type strain (strain Z-517) of "Methanothrix thermoacetophila" ("Methanosaeta thermoacetophila") was not validly published because it was not based on an axenic culture (17), and the level of taxonomic relatedness between strains Z-517 and CALS-1 is not known. (Patel and Sprott have indicated that strain Z-517 has been purified and now is available as a pure culture [21], but no information about the taxonomic characteristics of the pure culture has been published.) Very recently, we isolated a new thermophilic Methanothrix ("Methanosaeta") strain, strain $\mathrm{P}_{\mathrm{T}}^{\mathrm{T}}(\mathrm{T}=$ type strain), from a thermophilic anaerobic digestor and described its properties (11). In this study, we chemotaxonomically characterized three thermophilic Methanothrix strains, including our isolate, and compared them with Methanothrix soehngenii ("Methanosaeta concilii"). We propose that a new species, Methanothrix thermophila, should be established and that the name "Methanothrix thermoacetophila" ("Methanosaeta thermoacetophila") should be rejected.

\section{MATERIALS AND METHODS}

Sources of microorganisms. Methanothrix soehngenii ("Methanosaeta concilii") Opfikon (= DSM 2139), Methanothrix soehngenii FE (= DSM 3013), Methanothrix soehngenii GP6 (= DSM 3671), "Methanothrix thermoacetophila" ("Methanosaeta thermoacetophila") Z-517 (= DSM 
TABLE 1. Properties of Methanothrix strains ${ }^{a}$

\begin{tabular}{|c|c|c|c|c|c|}
\hline Species & Strain & $\begin{array}{l}\text { DSM } \\
\text { no. }\end{array}$ & $\begin{array}{l}\text { Optimum } \\
\text { temp }\left({ }^{\circ} \mathrm{C}\right)^{b}\end{array}$ & $\begin{array}{c}\text { Growth } \\
\text { factor }(\mathbf{s})^{c}\end{array}$ & $\begin{array}{l}\text { Guanine-plus-cytosine } \\
\text { content (mol\%) })^{d}\end{array}$ \\
\hline \multirow[t]{5}{*}{ Methanothrix soehngenii } & Opfikon $^{e}$ & 2139 & 37 & $\mathrm{SF}^{f}$ & 51.9 \\
\hline & $\mathrm{FE}^{e}$ & 3013 & 35 & $\mathrm{ND}^{g}$ & 52.6 \\
\hline & GP6 & 3671 & $35-40$ & SF, vitamins ${ }^{h}$ & 50.3 \\
\hline & $\mathrm{U}_{\mathrm{A}}^{e}$ & & 37 & ND & 51.1 \\
\hline & $\mathbf{P}_{\mathbf{M}}^{e}$ & & 37 & ND & 50.9 \\
\hline \multirow[t]{3}{*}{ Methanothrix thermophila } & CALS-1 & 3870 & 60 & CoM, biotin ${ }^{i}$ & 54.2 \\
\hline & Z-517 & 4774 & 55 & ME, vitamins ${ }^{j}$ & 54.3 \\
\hline & $P_{T}^{T}$ & 6194 & $55-60$ & $\mathrm{SF}^{f}$ & 52.7 \\
\hline
\end{tabular}

$a$ The cells of all of the strains were sheathed rods, and all of the strains grew at a neutral pH (data from references 9 through $11,17,20,21$, and 26 through 28 ) and were not susceptible to lysis.

${ }^{b}$ Data from references 9 through $11,17,20,21$, and 26 through 28 .

c SF, sludge fluid; CoM, coenzyme $\mathrm{M}$ (mercaptoethane sulfonate); $\mathrm{ME}$, manure extract.

${ }^{d}$ Data for strains Opfikon, FE, GP6, $\mathrm{U}_{\mathrm{A}}, \mathrm{P}_{\mathrm{M}}$, and $\mathrm{P}_{\mathrm{T}}{ }^{\mathrm{T}}$ from references 10,11 , and 26.

e Highly purified culture.

${ }^{f}$ Sludge fluid had a stimulatory effect but was not required $(9,11)$.

$g$ ND, not determined.

${ }^{h}$ Sludge fluid and vitamins had a stimulatory effect but were not required $(20,21)$.

${ }^{i}$ Coenzyme $M$ had a stimulatory effect but was not required (28).

j Manure extract and vitamins had a stimulatory effect but were not required $(17,21)$.

4774), and Methanothrix sp. strain CALS-1 (= DSM 3870) were obtained from the Deutsche Sammlung von Mikroorganismen und Zellkulturen GmbH (DSM), Braunschweig, Germany. Methanothrix soehngenii $\mathrm{U}_{\mathrm{A}}$ and $\mathrm{P}_{\mathrm{M}}$ and Methanothrix sp. strain $\mathrm{P}_{\mathrm{T}}^{\mathrm{T}}$ (= DSM $6194^{\mathrm{T}}$ ) were obtained in our laboratory $(10,11)$. The cultures of mesophilic strains Opfikon, $\mathrm{FE}, \mathrm{U}_{\mathrm{A}}$, and $\mathrm{P}_{\mathrm{M}}$ were highly purified but not axenic $(10,21,26)$. However, these cultures were considered to be pure enough for analyses of protein patterns of whole cells, 16S rRNA sequences, and DNA base compositions, as well as the other physiological studies described below.

Cultivation. Methanothrix soehngenii Opfikon, FE, GP6, $\mathrm{U}_{\mathrm{A}}$, and $\mathrm{P}_{\mathrm{M}}$ and Methanothrix sp. strain $\mathrm{P}_{\mathrm{T}}{ }^{\mathrm{T}}$ were cultivated on DSM medium 334 (5). Methanothrix sp. strain CALS-1 and "Methanothrix thermoacetophila" Z-517 were cultivated on DSM medium 387 (5). Unless otherwise stated, all of the strains were cultured at $37^{\circ} \mathrm{C}$ (strains Opfikon, FE, GP6, $\mathrm{U}_{\mathrm{A}}$, and $\mathrm{P}_{\mathrm{M}}$ ) or $55^{\circ} \mathrm{C}$ (strains CALS-1, Z-517, and $\mathrm{P}_{\mathrm{T}}{ }^{\mathrm{T}}$ ) in $125-\mathrm{ml}$ serum vials containing $30 \mathrm{ml}$ of medium or in $1,000-\mathrm{ml}$ bottles containing $500 \mathrm{ml}$ of medium under an $\mathrm{N}_{2}-\mathrm{CO}_{2}(80 / 20$, vol/vol $)$ atmosphere. The serum vials were closed with butyl rubber stoppers that were sealed with aluminum crimps.

Electrophoresis. Sodium dodecyl sulfate (SDS)-polyacrylamide gel electrophoresis was performed as described by Laemmli (12), using a gradient gel containing 4 to $20 \%$ acrylamide. Portions (approximately $5 \mu \mathrm{g}$ ) of denatured protein from whole cells were loaded on the gel, and bovine milk $\alpha$-lactalbumin (molecular mass, $14 \mathrm{kDa}$ ), soybean trypsin inhibitor $(20 \mathrm{kDa})$, bovine erythrocyte carbonic anhydrase $(30 \mathrm{kDa})$, egg white ovalbumin $(43 \mathrm{kDa})$, bovine serum albumin $(67 \mathrm{kDa})$, and rabbit muscle phosphorylase $b$ ( $94 \mathrm{kDa})$ were used as the $M_{\mathrm{r}}$ standards. The gel was stained with Coomassie brilliant blue R-250.

Determination of DNA base composition. We determined the DNA base compositions of strains Z-517 and CALS-1 in this study. DNA base composition data for the other strains were obtained from previously published papers $(10,11,26)$. DNA was extracted and purified by using the methods of Beji et al. (2) and Saito and Miura (22). The purified DNA was hydrolyzed with P1 nuclease (GC kit; Yamasa Shoyu Co., Chiba, Japan) and then with alkaline phosphatase from Escherichia coli (Wako Pure Chemicals Industries, Ltd.,
Osaka, Japan), as described by Tamaoka and Komagata (25). Guanine-plus-cytosine contents were determined by reversed-phase high-performance liquid chromatography (Shimadzu model LC-6A system). Separation was achieved at $40^{\circ} \mathrm{C}$ by using a flow rate of $1 \mathrm{ml} / \mathrm{min}$, a column of CLC-ODS (Shimadzu), and 5\% methanol in $10 \mathrm{mM}$ phosphate buffer ( $\mathrm{pH} 3.5$ ) as the mobile phase. Each deoxyribonucleoside was detected by determining the $A_{260}$, and an equimolar mixture of four deoxyribonucleosides was used as the standard.

16S rRNA sequencing. We determined partial 16S rRNA sequences for strains Opfikon, GP6, $U_{A}, P_{M}, C A L S-1$, $\mathrm{Z}-517$, and $\mathbf{P}_{\mathbf{T}}{ }^{\mathrm{T}}$. The RNA was extracted by using previously described methods $(13,19)$. Partial $16 S$ rRNA sequences were determined by using the reverse transcriptase procedure (13). In this procedure, we used three nucleotide primers that were complementary to universally conserved regions, TACCGCGGCGGCTGGC (position 520, reverse direction), CAATTCCTTTAAGTTTC (position 920, reverse direction), and ACGGGCGGTGTGTGC (position 1400, reverse direction) (E. coli $16 \mathrm{~S}$ rRNA numbering). These primers were made by using an ABI model 381A DNA synthesizer. The DNA sequences were determined by the dideoxynucleotide chain termination method (23).

Lipid analysis. The membrane polar lipids of strain $P_{T}{ }^{T}$ were extracted and analyzed by using a previously described method (16).

Other methods. Physiological characteristics were determined by using the minimal standards described by Boone and Whitman (4).

\section{RESULTS AND DISCUSSION}

Morphological and physiological characteristics. Table 1 summarizes the morphological and physiological properties of three thermophilic and five mesophilic Methanothrix strains. The data for optimum temperature, $\mathrm{pH}$ at which growth occurred, and growth factors were obtained from previous reports $(9-11,17,20,21,26-28)$. All of the strains had characteristic sheathed structures in which a number of cells were arranged. The cells were nonmotile straight rods with flat ends and were gram negative. The mean dimensions of single cells were 0.8 to 1.3 by 2 to $6 \mu \mathrm{m}$, and cells were 


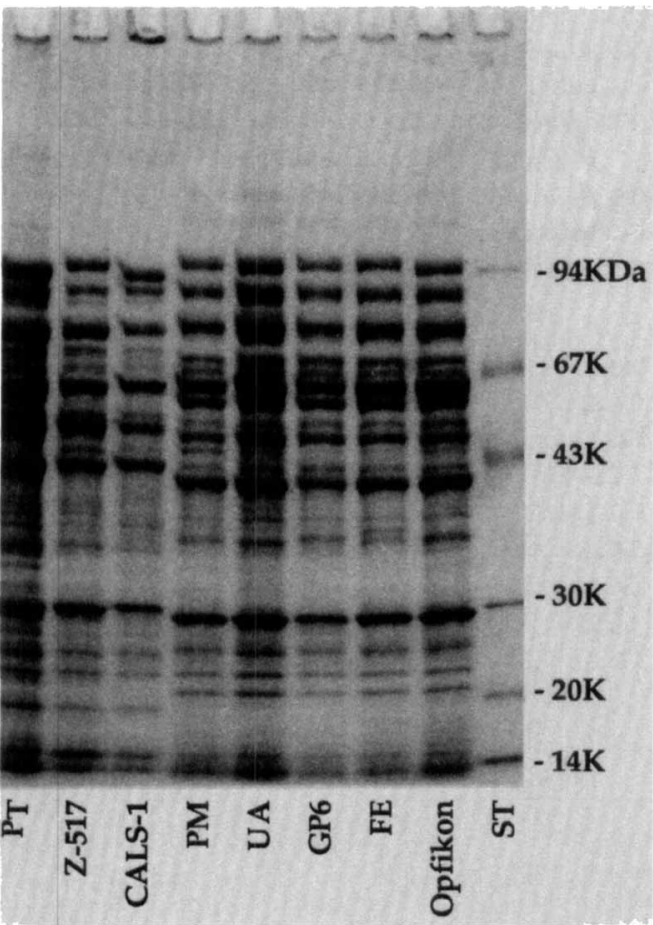

FIG. 1. Protein patterns for three strains of Methanothrix thermophila and five strains of Methanothrix soehngenii as determined by SDS-polyacrylamide gel electrophoresis. Electrophoresis was performed with a 4 to $20 \%$ acrylamide gel. Lane ST, $M_{\mathrm{r}}$ standards.

sometimes connected to each other. The sheathed filaments of the thermophiles were generally much shorter (length, 10 to $100 \mu \mathrm{m})$ than those of the mesophiles $(>100 \mu \mathrm{m})$. The cells were not susceptible to lysis by SDS or hypotonic conditions at room temperature when we used the procedures described by Boone and Whitman (4).

As described previously, one of the characteristics that differentiated the thermophiles from the mesophiles group was the fact that the thermophiles contained phase-refractive particles, probably gas vesicles, within their cells (11, 17,28 ). These particles could be readily eliminated by centrifugation or sonication. However, in strain Z-517 we did not observe these particles, whereas Nozhevnikova and Chudina observed them in their original culture (17).

DNA base composition. The guanine-plus-cytosine contents of the DNAs of strains CALS-1 and Z-517 were calculated to be 54.2 and $54.3 \mathrm{~mol} \%$, respectively. The values for the other strains were obtained from previous reports $(10,11,26)$ (Table 1$)$.

Protein patterns of whole cells. The protein patterns for the whole cells of the three thermophiles, as determined by SDS-polyacrylamide gel electrophoresis, were almost identical (Fig. 1), and these patterns were quite distinct from those of the mesophiles.

Partial 16S rRNA sequences. Figure 2 shows an alignment of the partial 16S rRNA sequences obtained for three thermophiles and four mesophiles. Sequence information was obtained for approximately 540 bases (ca. 37\% of all of the 16S rRNA bases). The alignment was optimized by using the secondary structure of Methanobacterium formicicum DSM 1312 (15). The sequence for strain Opfikon determined by us was identical to that determined previously by Eggen et al. (7), suggesting a high fidelity of sequencing from the RNA template. Table 2 shows the levels of sequence homology and the numbers of base differences for the seven strains. Within the thermophilic group, the strain $\mathrm{P}_{T}{ }^{\mathrm{T}}$ sequence exhibited $100 \%$ similarity with the sequence of strain Z-517, while there were six base differences between strains $P_{T}{ }^{T}$ and CALS-1. Our comparative analysis of the 16S rRNAs revealed a considerable difference between the thermophiles and the mesophiles. Within the mesophilic group, the strains exhibited more than $99 \%$ similarity with each other, and this finding was in close agreement with the results of the DNA-DNA hybridization studies of Touzel et al. (26), who used strains FE, GP6, and Opfikon. However, the members of the thermophilic group exhibited less than $95 \%$ similarity (corresponding to 29 to 34 base differences) to the mesophiles, suggesting that the thermophilic group is quite distant from any of the mesophilic Methanothrix strains.

Nomenclature of thermophilic strains belonging to the genus Methanothrix. The thermophilic Methanothrix strains form a taxon which is phenotypically and genotypically distinguishable from the mesophilic group of the genus Methanothrix. However, as described above, the partial 16S rRNA sequence of strain CALS-1 was different from the sequences of strains $\mathrm{Z}-517$ and $\mathrm{P}_{\mathrm{T}}{ }^{\mathrm{T}}$ at six positions, indicating that the thermophilic Methanothrix strains apparently should be separated into two genogroups.

In this study, the two genogroups could not be differentiated by any of conventional methods used for characterization (Table 1). In general, a species should be established with phenotypic characteristics which apparently distinguish the species from allied species. Therefore, we are reluctant to separate the thermophilic Methanothrix strains into two species and propose that the two genogroups should be assigned to a single species.

In the thermophilic Methanothrix group, "Methanothrix thermoacetophila" ("Methanosaeta thermoacetophila") is the name that has been given to strain Z-517 $(17,21)$. However, the description of "Methanothrix thermoacetophila" was inadequate because it was based on an enriched culture (17), and the name is invalid according to the International Code of Nomenclature of Bacteria (Rule 31a) (14). In this paper we propose the name Methanothrix thermophila sp. nov. for the thermophilic strains of the genus Methanothrix. The type species is strain $\mathrm{P}_{\mathrm{T}}$ (= DSM 6194). Methanothrix thermophila contains two genogroups which differ in their 16S rRNA sequences. Genogroup 1 consists of strains $\mathrm{P}_{\mathrm{T}}{ }^{\mathrm{T}}$ (= DSM $\left.6194^{\mathrm{T}}\right)$ and Z-517 (= DSM 4774), and genogroup 2 contains strain CALS-1 (= DSM 3870).

Description of Methanothrix thermophila sp. nov. Methanothrix thermophila (ther. mo' phi. la. Gr. adj. thermos, hot; Gr. adj. philos, loving; Gr. adj. thermophila, heat loving) is a thermophilic (optimum growth occurs at 55 to $60^{\circ} \mathrm{C}$ ), rod-shaped, sheathed, strictly anaerobic, aceticlastic methanogen that belongs to the genus Methanothrix ("Methanosaeta"). Methanothrix thermophila is apparently distinct from Methanothrix soehngenii ("Methanosaeta concilii") because of its thermophily and 16S rRNA sequence. Cells are nonmotile, strictly anaerobic rods with flat ends and are gram negative. The mean dimensions of single cells are 0.8 to 1.3 by 2 to $6 \mu \mathrm{m}$. Cells are enclosed inside an annular, striated sheathed structure and are separated by partitions that have a concentric structure. Cells grow in the form of loose sediment, and culture broth exhibits opalescent turbidity after gentle shaking. Most of the sheathed filaments are less than $100 \mu \mathrm{m}$ long, and they do not form bundles or the cottonlike flocs which are common in Methanothrix soeh- 
1. M. formicicum DSM1312

2. Opfikon

3. GP6

4. $\mathrm{UA}_{\mathrm{A}}$

5. PM

7. Z517

8. PT
6. CALS-1

271

281

291

301

311

GGGUUGUGAG AGCAAGAGCC CGGAGAUGGA ACCUGAGACA AGGUUCCAGG GGGUUGUGAG AGCAAGAGCC CGGAGAUGGA UUCUGAGACA CGAAUCCAGG GOGUUGUGAG AGCAAGAGCC CGGAGAUGGA UUCUGAGACA CGAAUCCAGG GGGUUGUGAG AGCAAGAGCC CGGAGAUGGA UUCUGAGACA CGAAUCCAGG GGGUUGUGAG AGCAAGAGCC CGGAGAUGGA UUCUGAGACA CGAAUCCAGG GGGUUGUGAG AGCAAGAGCC CGGAGAUGGA UUCUGAGACA UGAAUCCAGG GGGUUGUGAG AGCAAGAGCC CGGAGAUGGA UUCUGAGACA UGGAAUCCAGG GGGUUGUGAG AGCAAGAGCC CGGAGAUGGA UUCUGAGACA UGGAUCCAGG
321
331
341
351
361
371
381

1. CCCUACGGGG CGCAGCAGGC GCGAAA CCUC CGCAAU GCAC GAAAGUGCGA OGGGGGAAAC CCAAGUGCCA

2. CCCUACGGGG UGCAGCAGGC GCGAAAACUU UACAAUGCUG GCAACAGCGA UAAGGGAACC UCGAGUGCCA

3. CCCUACGGGG UGCAGCAGGC GCGAAAACUU UACAAUGCUG GCAACAGCGA UAAGGGAACC UCGAGUGCCA

4. CCCUACGGGG UGCAGCAGGC GCGAAAACUU UACAAUGCUG GCAACAGCGA UAAGGGAACC UCGAGUGCCA

5. CCCUACGGGG UGCAGCAGGC GCGAAAACUU UACAAUGCUG GCAACAGCGA UAAGGGAACC UCGAGUGCCA

6. COCUACGGGG UGCAGCAGGC GCGAAAACUU UACAAUGCGG GCAACCGCGA UAAGGGGACC UCGAGUGCUG

7. COCUACGGGG UGCAGCAGGC GCGAAAACUU UACAAUGCGG GCAACCGGCNA UAAGGGGACC UCGAGUGCUG

8. CCCUACGGGG UGCAGCAGGC GCGAAAACUU UACAAUGCGG GCAACCGCGA UAAGGGGACC UCGAGUGCUG
391
401
411
421

1. CUCUUAACGG GGUGGCUUUU CUUAAGUGUA AAAAGCUUUU

2. G-GUUACNNA UCUGGCUGUC GANAUGCCUA AAAAGCAUUU

3. G-GUUACAAA UCUGGCUGUC GANAUGCCUA AAAAGCAUUU

4. G-GUUACNNA UCUGGCUGUC GANAUGCCUA AAAAGCAUUU

5. G-GUUACNNA UCUGGCUGUC GANAUGCCUA AAAAGCAUUU

6. G-GUUACAAA $\subseteq C U G G C U U U U$ GGGCUGCCUA AAAAGCAGU $\subseteq$

7. G-GUUACAAA CCCUGGCUGU GGG CUGCCUA AAAAGCAGU

8. G-GUUACAAA CCUGGCUGUU GGG CUGCCUA AAAAGCAGUC
641
651
661
671
681
691
701

1. AUAAUCCCGG GAGGACCACC UGUGGCGAAG GCGGCUAACU GGAACGGGCC UGACGGUGAG UAACGAAAGC

2. GUAAUCCUUG AAGGACCACC AGUGGCGAAG GCGUCUCACC AGAACGGAAC UGACGGCAAG GGACGAAA GC

3. GUAAUCCUUG AAGGACCACC AGUGGCGAAG GCGUCUCACC AGAACGGAAC UGACGGCAAG GGACGAAA GC

4. GUAAUCCUUG AAGGACCACC AGUGGCGAAG GCGUCUCACC AGAACCGAAC UGACGGCAAG GGACGAAA GC

5. GUAAUCCUUG AAGGACCACC AGUGGCGAAG GCGUCUCACC AGAACGGAAC UGACGGCAAG GGACGAAA GC

6. GUAAUCCUUG AGGGACCACC AGUGGCGAAG GCGUCUCACC AGAACGGAUC CGACGGCAAG GGACGAAAGC

7. GUAAUCCUCG AGGGACCACC AGUGGCGAAG GCGUCUCACC AGAACGGAŨC ÇGACGGCAAG GGACGAAA GC

8. GUAAUCCUÇG AGGGACCACC AGUGGCGAAG GCGUCUCACC AGAACGGAŨC ÇGACGGCAAG GGACGAAA GC
711
721
731
741
751
761
771

1. CAGGGGCGCG AACCGGAUUA GAUACCCGGG UAGUCCUGGC CGUAAACGAU GUGGACUUGG UGUUGGGAUG

2. UAGGGGCACG AACCGGAUUA GAUACCCGGG UAGUCCUAGC CGUAAACGAU ACUCGCUAGG UGUCGGC-AC

3. UAGGGGCACG AACCGGAUUA GAUACCCGGG UAGUCCUAGC CGUAAACGAU ACUCGCUAGG UGUCGGC-AC

4. UAGGGGCACG AACCGGAUUA GAUACCCGGG UAGUCCUAGC CGUAAACGAU ACUCGCUAGG UGUCGGC-AC

5. UAGGGGCACG AACCGGAUUA GAUACCCGGG UAGUCCUAGC CGUAAACGAU ACUCGCUAGG UGUCGGC-AC

6. UAGGGGCACG AACCGGAUUA GAUACCCGGG UAGUCCUAGC CGUAAACGAU ACUCGCUAGG UGUCGGC-AC

7. UAGGGGCACG AACCGGAUUA GAUACCCGGG UAGUCCUAGC CGUAAACGAU ACUCGCUAGG UGUCGGC-AC

8. UAGGGGCACG AACCGGAUUA GAUACCCGGG UAGUCCUAGC CGUAAACGAU ACUCGCUAGG UGUCGGC-AC
781
791
801
811
821
831
1. GCU CCGAGCU GCCCCAGUGC CGAAGGGAAG CUGUUAAGUC CACCGCCUGG GAAGUACG
2. GGU GCGACCG UUGUCGGUGC CGUAGGGAAG CCGUGAAGCG AGCCACCUGG GAAGU
3. GGU GCGACCG UUGUCGGUGC CGUAGGGAAG CCGUGAAGCG AGCCACCUGG GAAGU
4. GGU GCGACCG UUGUCGGUGC CGUAGGGAAG CCGUGAAGCG AGCCACCUGG GAAGU
5. GGUGCGACCG UUGUCGGUGC CGUAGGGAAG CCGUGAAGCG AGCCACCUGG GAAGU
6. GGUGCGACCG UUGUCGGUGC CGUAGGGAAG CCGUGAAGCG AGCCACCUGG GAAGU
7. GGUNNGACCG UUGUCGGUGC CGUAGGGAAG CCGUGAAGCG AGCCACCUGG GAAGU
8. GGUG CGACCG UUGUCGGUGC CGUAGGGAAG CCGUGAAGCG AGCCACCUGG GAAGU

FIG. 2. Partial 16S rRNA sequences for three strains of Methanothrix thermophila and five strains of Methanothrix soehngenii. The sequences are aligned with the known complete sequence for Methanobacterium formicicum (15). A, adenine; U, uracil; C, cytosine; G, guanine; $N$, ambiguous nucleotide. The dashes indicate positions that were deleted in the sequences. The underlined bases are bases that were different from those of Methanothrix soehngenii Opfikon. 


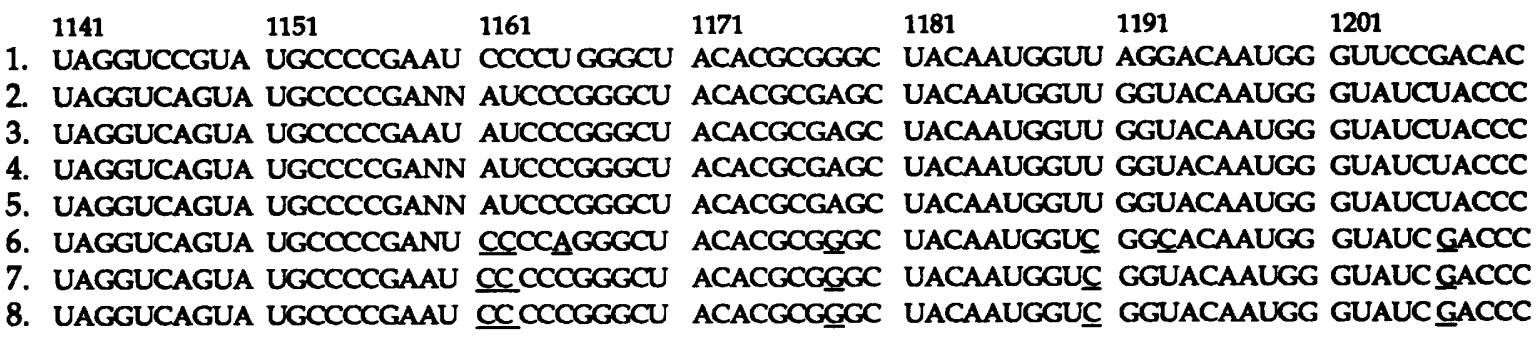

$\begin{array}{lllllll}1211 & 1221 & 1231 & 1241 & 1251 & 1261 & 1271\end{array}$

1. UGAAAGGUGG AGGUAAUCUC CUAAACCUGG CCUUAGUUCG GAUUGAGGGC UGUAACUCGC CCUCAUGAAG

2. CGAAAGGGGA CGGGAAUCUC CUAAAACCAA UCUUAGUUCG GAUUGAGGGC UGCAACUCGC CCUCAUGAAG

3. CGAAAGGGGA CGGGAAUCUC CUAAAACCAA UCUUAGUUCG GAUUGAGGGC UGCAACUCGC CCUCAUGAAG

4. CGAAAGGGGA CGGGAAUCUC CUAAAACCAA UCUUAGUUCG GAUUGAGGGC UGCAACUCGC CCUCAUGAAG

5. CGAAAGGGGA CGGGAAUCUC CUAAAACCAA UCUUAGUUCG GAUUGAGGGC UGCAACUCGC CCUCAUGAAG

6. CGAGAGGGGU AGGCAAUCCC CUAAAGCCGA UCGUAGUUCG GAUUGAGGGC UGAAACUCGC CCUCAUGAAG

7. CGAAAGGGGU AGGCAAUCCC CUAAAACCGA UCGUAGUUCG GAUUGAGGGC UGAAACUCGC CCUCAUGAAG

8. CGAAAGGGGU AGGC्AAUCCCC CUAAAACCGA UCGUAGUUCG GAUUGAGGGC UGAAACUCGC CCUCAUGAAG

$\begin{array}{lllll}1281 & 1291 & 1301 & 1311 & 1321\end{array}$

1. CUGGAAUGCG UAGUAAUCGC GUGUCAUAAC CGCGCGGUGA AUACGUCCCU

2. CUGGAAUCCG UAGUAAUCGC GUUUCAACAG AACGCGGUGA AUACGU

3. CUGGAAUCCG UAGUAAUCGC GUUUCAACAG AACGCGGUGA AUACGU

4. CUGGAAUCCG UAGUAAUCGC GUUUCAACAG AACGCGGUGA AUACGU

5. CUGGAAUCCG UAGUAAUCGC GUUUCAACAG AACGCGGUGA AUACGU

6. CUGGAAUCCG UAGUAAUCGC GUUUCAACAG AACGCGGUGA AUACGU

7. CUGGAAUCCG UAGUAAUCGC GUUUCAACAG AACGCGGUGA AUACGU

8. CUGGAAUCCG UAGUAAUCGC GUUUCAACAG AACGCGGUGA AUACGU

FIG. 2-Continued.

ngenii. Colonies are sometimes observed in acetate agar medium when high cell concentrations are present $(11,28)$. Gas vesicles are often observed inside the cells. Cells are not susceptible to lysis by SDS or hypotonic conditions at room temperature, but cells are lysed by SDS at $60^{\circ} \mathrm{C}$.

The intensity of autofluorescence (405-nm excitation) is higher than that for Methanothrix soehngenii because of a higher content of coenzyme $F_{420}(11)$. Coenzyme $F_{420}$ with four glutamyl residues on the side chain is more abundant than the other coenzyme $F_{420}$ types, although the total coenzyme $F_{420}$ contents are much lower than the contents in other hydrogenotrophic methanogens (11). A tetraether type

TABLE 2. Levels of 16S rRNA sequence homology for four mesophilic and three thermophilic Methanothrix strains

\begin{tabular}{|c|c|c|c|c|c|c|c|}
\hline \multirow[b]{2}{*}{ Strain } & \multicolumn{7}{|c|}{$\begin{array}{l}\text { No. of base differences or \% homology with } \\
\text { strain }^{a} \text { : }\end{array}$} \\
\hline & $\begin{array}{l}5 \\
\text { 递 } \\
\text { o }\end{array}$ & $\stackrel{0}{0}$ & $s^{4}$ & $\Sigma$ & $\begin{array}{l}\vec{b} \\
\overrightarrow{0}\end{array}$ & ลี & $\mathrm{r}^{2}$ \\
\hline Opfikon (= DSM 2139) & & 0 & 1 & 0 & 33 & 29 & 29 \\
\hline GP6 (= DSM 3671) & 100 & & 1 & 0 & 33 & 29 & 29 \\
\hline $\mathrm{U}_{\mathrm{A}}$ & $>99$ & $>99$ & & 1 & 34 & 30 & 30 \\
\hline & 100 & 100 & $>99$ & & 33 & 29 & 29 \\
\hline CALS-1 (= DSM 3870) & 94 & 94 & 94 & 94 & & 6 & 6 \\
\hline Z-517 (= DSM 4774) & 95 & 95 & 94 & 95 & 99 & & 0 \\
\hline $\bar{P}_{T}^{T}\left(=\mathrm{DSM} 6194^{\mathrm{T}}\right)$ & 95 & 95 & 94 & 95 & 99 & 100 & \\
\hline
\end{tabular}

${ }^{a}$ The values on the upper right are the numbers of base differences, and the values on the lower left are the percentages of homology (calculated from the data in Fig. 2). (dibiphytanediyl-diglycerol tetraether; caldarchaeol) of lipid is found in strain $\mathbf{P}_{\mathbf{T}} \mathbf{T}$.

The optimum temperature for growth and methanogenesis is 55 to $60^{\circ} \mathrm{C}$, depending on the strain $(11,17,21,28)$. The optimum $\mathrm{pH}$ is around 7 . Acetate is the only substrate used for growth and methanogenesis $(11,17,28)$. Neither methanogenesis nor growth is observed when $\mathrm{H}_{2}-\mathrm{CO}_{2}$, formate, methylamines, or methanol is used for the substrate $(11,17$, $28)$. Formate is not split into $\mathrm{H}_{2}$ and $\mathrm{CO}_{2}(11,28) . \mathrm{NaCl}$ is not required for growth (11). Coenzyme $M$ (mercaptoethane sulfonate), vitamins, manure extract, or sludge fluid stimulates growth $(11,17,28)$. Chloramphenicol $(5 \mu \mathrm{g} / \mathrm{ml})$, bacitracin $(10 \mu \mathrm{g} / \mathrm{ml})$, neomycin $(10 \mu \mathrm{g} / \mathrm{ml})$, tetracycline (100 $\mu \mathrm{g} / \mathrm{ml})$, and kanamycin $(100 \mu \mathrm{g} / \mathrm{ml})$ inhibit growth and methanogenesis (11).

The DNA base composition ranges from 52.7 to $54.3 \mathrm{~mol} \%$ guanine plus cytosine as determined by high-performance liquid chromatography (Table 1). The 16S rRNA sequence is quite distinct from that of Methanothrix soehngenii (level of similarity, less than 95\%). The type strain of Methanothrix thermophila is strain $\mathrm{P}_{\mathrm{T}}$ (= DSM 6194). Methanothrix thermophila contains two genogroups. Genogroup 1 consists of strains $\mathrm{P}_{\mathrm{T}}^{\mathrm{T}}$ (= DSM 6194 ${ }^{\mathrm{T}}$ ) and Z-517 (= DSM 4774), and genogroup 2 contains strain CALS-1 (= DSM 3870). The partial 16S rRNA sequences described above have been submitted to the National Institute of Genetics, Shizuoka, Japan.

\section{ACKNOWLEDGMENTS}

We thank Kazuo Komagata (Tokyo University of Agriculture), Tsuyoshi Morinaga (Daicel Chemical Industries, Ltd.), Ken-ichiro Suzuki (Japan Collection of Microorganisms, Institute of Physical 
and Chemical Research, RIKEN), and Ko Imai (Institute for Fermentation, Osaka, Japan) for their helpful suggestions.

This work was supported by a grant from the New Energy and Industrial Technology Development Organization (Research and Development on New Wastewater Treatment System).

\section{REFERENCES}

1. Barker, H. A. 1936. Studies upon the methane-producing bacteria. Arch. Mikrobiol. 7:420-438.

2. Beji, A., D. Izard, F. Gavini, H. Leclerc, M. Leseine-Delstanche, and J. Krembel. 1987. A rapid chemical procedure for isolation and purification of chromosomal DNA from gram-negative bacilli. Anal. Biochem. 162:18-23.

3. Boone, D. R. 1991. Strain GP6 is proposed as the neotype strain of Methanothrix soehngenii ${ }^{\mathrm{VP}}$ pro synon. Methanothrix conciliit $^{\mathrm{VP}}$ and Methanosaeta concilii ${ }^{\mathrm{VP}}$. Request for an opinion. Int. J. Syst. Bacteriol. 41:588-589.

4. Boone, D. R., and W. B. Whitman. 1988. Proposal of minimal standards for describing new taxa of methanogenic bacteria. Int. J. Syst. Bacteriol. 38:212-219.

5. Deutsche Sammlung von Mikroorganismen und Zellkulturen GmbH. 1989. Catalogue of strains, 4th ed. Gesellschaft für Biotechnologische Forschung $\mathrm{GmbH}$, Braunschweig, Germany.

6. Dolfing, J., A. Griffioen, A. R. W. van Neerven, and L. P. T. M. Zevenhuizen. 1985. Chemical and bacteriological composition of granular methanogenic sludge. Can. J. Microbiol. 31:744-750.

7. Eggen, R., H. Harmsen, A. Geerling, and W. M. de Vos. 1989. Nucleotide sequence of a 16S-rRNA encoding gene from the archaebacterium Methanothrix soehngenii. Nucleic Acids Res. 17:9469.

8. Fathepure, B. 1983. Isolation and characterization of an aceticlastic methanogen from a biogas digester. FEMS Microbiol. Lett. 19:151-156.

9. Huser, B. A., K. Wuhrmann, and A. J. B. Zehnder. 1982. Methanothrix soehngenii gen. nov. sp. nov., a new acetotrophic non-hydrogen-oxidizing methane bacterium. Arch. Microbiol. 132:1-9.

10. Kamagata, Y., and E. Mikami. 1990. Some characteristics of two morphotypes of Methanothrix soehngenii from mesophilic anaerobic digesters. J. Ferment. Bioeng. 70:272-274.

11. Kamagata, Y., and E. Mikami. 1991. Isolation and characterization of a novel thermophilic Methanosaeta strain. Int. J. Syst. Bacteriol. 41:191-196.

12. Laemmli, U. K. 1970. Cleavage of structural proteins during the assembly of the head of bacteriophage T4. Nature (London) 227:680-685.

13. Lane, D. J., B. Pace, G. J. Olsen, D. A. Stahl, M. L. Sogin, and N. R. Pace. 1985. Rapid determination of $16 \mathrm{~S}$ ribosomal RNA sequences for phylogenetic analyses. Proc. Natl. Acad. Sci. USA 82:6955-6959.

14. Lapage, S. P., P. H. A. Sneath, E. F. Lessel, V. B. D. Skerman,
H. P. R. Seeliger, and W. A. Clark (ed.). 1975. International code of nomenclature of bacteria. 1976 Revision. American Society for Microbiology, Washington, D.C.

15. Lechner, K., G. Wich, and A. Boeck. 1985. The nucleotide sequence of the 16S rRNA gene and flanking regions from Methanobacterium formicicum: the phylogenetic relationship between methanogenic and halophilic archaebacteria. Syst. Appl. Microbiol. 6:157-163.

16. Nishihara, M., Morii, H., and Y. Koga. 1987. Structure determination of a quartet of novel tetraether lipids from Methanobacterium thermoautotrophicum. J. Biochem. 101:1007-1015.

17. Nozhevnikova, A. N., and V. I. Chudina. 1985. Morphology of the thermophilic acetate methane-producing bacterium Methanothrix thermoacetophila sp. nov. Microbiology (Engl. Transl. Mikrobiologiya) 53:618-624.

18. Ohtsubo, S., H. Miyahara, K. Demizu, S. Kohno, and I. Miura. 1991. Isolation and characterization of new Methanothrix strains. Int. J. Syst. Bacteriol. 41:358-362.

19. Oyaizu, H., and C. R. Woese. 1985. Phylogenetic relationships among the sulfate respiring bacteria, myxobacteria and purple bacteria. Syst. Appl. Microbiol. 6:257-263.

20. Patel, G. B. 1984. Characterization and nutritional properties of Methanothrix concilii sp. nov., a mesophilic, aceticlastic methanogen. Can. J. Microbiol. 30:1383-1396.

21. Patel, G. B., and G. D. Sprott. 1990. Methanosaeta concilii gen nov., sp. nov. (“Methanothrix concilii") and Methanosaeta thermoacetophila nom. rev., comb. nov. Int. J. Syst. Bacteriol. 40:79-82.

22. Saito, H., and K. Miura. 1963. Preparation of transforming deoxyribonucleic acid by phenol treatment. Biochim. Biophys. Acta 72:619-629.

23. Sanger, F., S. Nicklen, and A. R. Coulson. 1977. DNA sequencing with chain-terminating inhibitors. Proc. Natl. Acad. Sci. USA 74:5463-5467.

24. Söhngen, N. L. 1910. Sur le rôle du méthane dans la vie organique. Rev. Trav. Chim. 29:238-274.

25. Tamaoka, J., and K. Komagata. 1984. Determination of DNA base composition by reversed-phase high-performance liquid chromatography. FEMS Microbiol. Lett. 25:125-128.

26. Touzel, J. P., G. Prensier, J. L. Roustan, I. Thomas, H. C. Dubourguier, and G. Albagnac. 1988. Description of a new strain of Methanothrix soehngenii and rejection of Methanothrix concilii as a synonym of Methanothrix soehngenii. Int. J. Syst. Bacteriol. 38:30-36.

27. Zehnder, A. J. B., B. A. Huser, T. D. Brock, and K. Wuhrmann. 1980. Characterization of an acetate-decarboxylating, non-hydrogen oxidizing methane bacterium. Arch. Microbiol. 124:111.

28. Zinder, S. H., T. Anguish, and A. L. Lobo. 1987. Isolation and characterization of a thermophilic acetotrophic strain of Methanothrix. Arch. Microbiol. 146:315-322. 